\title{
ZnO Thin Films Prepared by Pulsed Laser Deposition
}

\author{
M. G. Tsoutsouva ${ }^{1}$, C. N. Panagopoulos ${ }^{1 *}$, D. Papadimitriou ${ }^{2}$, I. Fasaki ${ }^{3}$, M. Kompitsas ${ }^{3}$, \\ N. Galanis ${ }^{4}$, D. E. Manolakos ${ }^{4}$
}

${ }^{1}$ Laboratory of Physical Metallurgy, National Technical University of Athens, Zografos, 15780, Athens, Greece ${ }^{2}$ National Technical University of Athens, Department of Physics, GR-15780 Athens

${ }^{3}$ Theor. and Phys./Chem. Institute, National Hellenic Research Foundation, 48 Vas. Konstantinou Ave., 11635, Athens, Greece

${ }^{4}$ Laboratory of Manufacturing Technology, National Technical University of Athens, 9 Iroon Polytechniou Avenue, 15780 Athens, Greece

\section{Introduction}

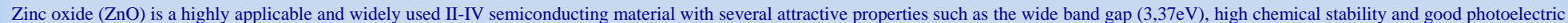

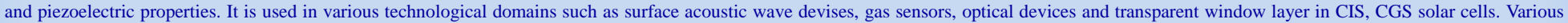

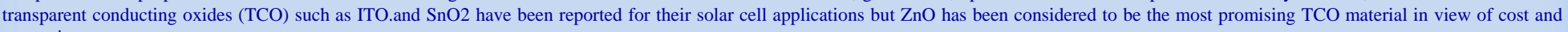
properties.

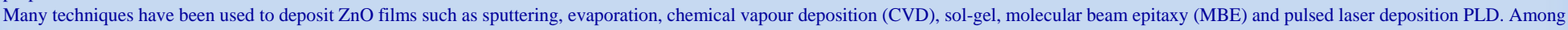

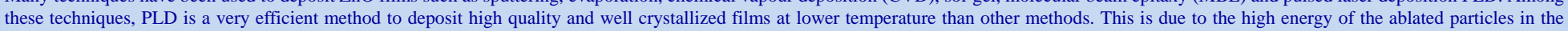
laser-produced plasma plume.

\section{Experimental Procedure}

ZnO films were deposited on glass substrates employing a typical homemade PLD system. All glass substrates were cleaned in an ultrasonic bath with acetone for $10 \mathrm{~min}$ before deposition. A UV pulsed $\mathrm{KrF}$ excimer laser operated at $248 \mathrm{~nm}$ with pulse frequency $10 \mathrm{~Hz}$, pulse duration $10 \mathrm{~ns}$ and fluence $2.6 \mathrm{~J} / \mathrm{cm}^{2}$ was used to evaporate the metallic $\mathrm{Zn}$ target. The metallic zinc disk (Aldrich 99,9\% purity), with diameter $2,5 \mathrm{~cm}$ and thickness $0,5 \mathrm{~cm}$ was placed parallel $5 \mathrm{~cm}$ away from the substrate. To avoid fast drilling, the target was placed on a vacuum compatible, computer-controlled XY stage synchronized with the pulsed laser. The deposition chamber was initially evacuated to a base pressure $10^{-4} \mathrm{~Pa}$, the substrate temperature was determined in situ during growth with a thermocouple placed below the substrate. At a fixed deposition time of 2 hours, the $\mathrm{ZnO}$ films were deposited at the substrate temperatures of 100 and $300{ }^{\circ} \mathrm{C}$ with oxygen partial pressures (flow) of 5, $10,20,30,40$ and $50 \mathrm{~Pa}$.

\section{Results and Discussion}

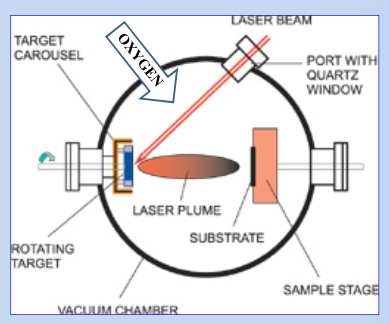

\section{Structural Properties}
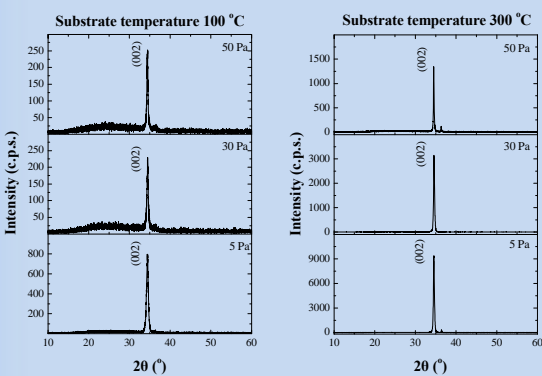

Figure 1: $X$-ray diffraction patterns of ZnO films grown at different oxygen pressures and two different substrate temperatures.

The increase of substrate temperature is shown to increase the $\mathrm{ZnO}$ (002) diffraction peak intensity (figure 1). It is believed that the temperature rise accelerates the migration of adatoms to the energy favorable positions, resulting in the enhancement of crystallinity of the $\mathrm{ZnO}$ films.

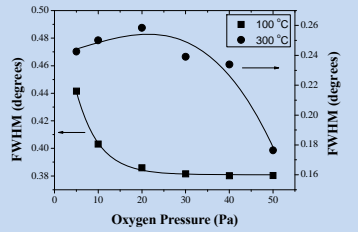

Figure 2: FWHM of the X-ray diffraction patterns for (002) peak of ZnO film.

The FWHM value of (002) peak is observed to decrease with increasing oxygen pressure from 5 to $50 \mathrm{~Pa}$ (figure 2). $\mathrm{ZnO}$ is always deviated from stoichiometry and presents intrinsic defects such as zinc interstitials and oxygen vacancies, especially at Zn-rich or O-deficient atmospheres. The number of these intrinsic defects could be decrease by the increase of partial-oxygen pressure, so the $\mathrm{ZnO}$ film becomes better crystalline [1].

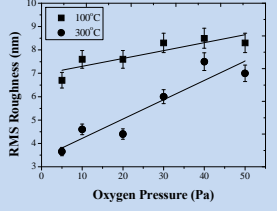

Figure 3: The dependence of RMS roughness of $\mathrm{ZnO}$ films, on substrate temperatures and oxygen pressures during deposition.

The surface roughness of $\mathrm{ZnO}$ films (figure 3) is seen to increase with increasing oxygen pressure during deposition. This tendency is similar to other reported investigations [2, 3].

\section{Optical Properties}

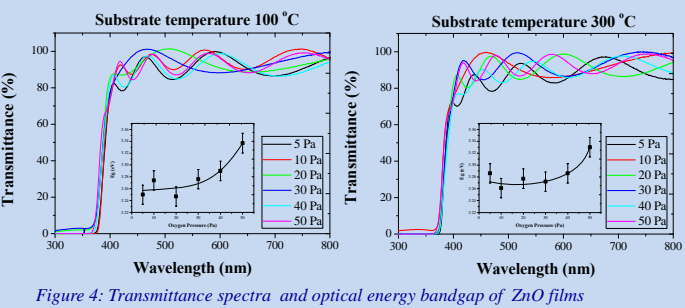

Figure 4: Transmittance spectra and optical energy bandgap of $\mathrm{ZnO}$ film

For the selected experimental conditions all the produced $\mathrm{ZnO}$ films show high transmission up to $90 \%$ in the visible region. The increase in oxygen pressure inhibits the evaporation of $\mathrm{O}$ atoms and favors the combination of $\mathrm{Zn}$ and $\mathrm{O}$ atoms during the deposition process. Accordingly the oxygen vacancy concentration is reduced as oxygen pressure increases, resulting in the increase of the optical band gap $\mathrm{E}_{\mathrm{g}}[4]$.

\section{References}

[1] J.-L. Zhao, X.-M. Li, J.-M. Bian, W.-D. Yu, Z.-D. Gao, J. Cryst. Growth, 276 (2005) 507

[2] S.S. Kim, B.T. Lee, Thin Solid Films 446 (2004) 307

[3] Z.G. Zhang, F. Zhou, X.Q. Wei, M. Liu, G. Sun, C.S. Chen, C.S. Xue, H.Z Zhuang, B.Y. Man, Physica E 39 (2007) 253

[4] L. Sun, W. Cheng, F. Lin, X. Ma, W. Shi, Physica B, 381 (2006) 109 [5] Y. Maa, G.T. Dua, T.P. Yanga, D.L. Qiub, X. Zhangb, H.J. Yanga, Y.T. Zhanga, B.J. Zhaoa, X.T. Yanga, D.L. Liua, J. Cryst. Growth, 255 (2003) 303 [6] F.K. Shana, G.X. Liua, W.J. Leea, G.H. Leea, I.S. Kima, B.C. Shina, Y.C. Kimb, J. Cryst. Growth, 277 (2005) 284-292

\section{Electrical Properties}
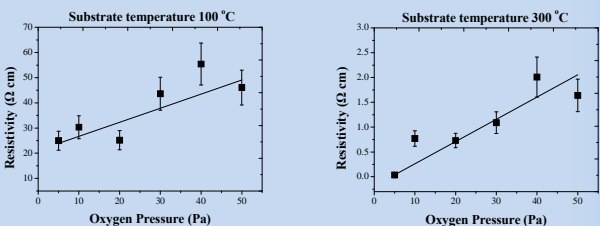

Figure 5: Dependence of $\mathrm{ZnO}$ resistivity on oxygen pressure and substrate temperature.

For both substrate temperatures, the electrical resistivity of $\mathrm{ZnO}$ films increases with increasing oxygen pressure from 5 to $50 \mathrm{~Pa}$. With increasing oxygen pressure, the concentration of $\mathrm{V}_{\mathrm{O}}$ decrease, leading to a higher electrical resistivity of $\mathrm{ZnO}$ thin films[5]. It is also found that the resistivity decreases with increasing substrate temperature. This phenomenon may be due to the enhancement of film crystallinity with increasing temperature and consequently the electron mobility increases [6].

\section{Conclusions}

- Zinc oxide $(\mathrm{ZnO})$ thin films were deposited on soda lime glass substrates by pulsed laser deposition (PLD) in an oxygenreactive atmosphere. High quality polycrystalline $\mathrm{ZnO}$ films with hexagonal wurtzite structure were deposited even at low substrate temperature of $100{ }^{\circ} \mathrm{C}$. In general the increase of substrate temperature and oxygen pressure was found to enhance the crystallinity of the $\mathrm{ZnO}$ films.

- The surface roughness of the deposited oxide films, was observed to be in the range of 2-9 $\mathrm{nm}$.

- The $\mathrm{ZnO}$ films exhibited high transmittance of $90 \%$ in the visible region at oxygen pressures ranging from 5 to $50 \mathrm{~Pa}$. The energy band gap and the thickness of the films calculated from the transmittance spectra were about $3.27 \mathrm{eV}$ and $500 \mathrm{~nm}$, respectively

The electrical resistivity of the $\mathrm{ZnO}$ films was found to decrease with increasing substrate temperature and decreasing oxygen pressure. 